\title{
A relação entre o Tribunal Penal Internacional e o Conselho de Segurança da
}

ONU: uma análise sobre o crime de agressão

Fernanda Graebin Mendonça ${ }^{1}$

\section{Resumo}

Após o término da Segunda Guerra Mundial, com a insurgência da necessidade de proteção de direitos básicos e inerentes aos seres humanos, é estabelecida a Declaração Universal dos Direitos do Homem (DUDH), que veio a fortalecer esta proteção aos direitos chamados humanos. Ao mesmo tempo, surge o que seria o organismo internacional de maior influência mundial: a Organização das Nações Unidas (ONU), encabeçado por seu órgão de maior poder, o Conselho de Segurança. Entretanto, devido ao crescente número de atos que atentavam contra a humanidade, era necessário, além de proclamar os direitos, garanti-los de forma eficiente. É neste contexto que, cerca de cinco décadas após o estabelecimento da DUDH e baseado em seus princípios, o Direito Internacional vê dele nascer um novo ramo: o Direito Penal Internacional materializado pela instituição de um importante órgão judicial em 1998, o Tribunal Penal Internacional. Apesar de constituir um grande avanço, a corte já nasce alvo de discussões e críticas, principalmente no que diz respeito à sua autonomia em relação ao Conselho de Segurança da ONU, e especialmente quanto ao crime de agressão arrolado pelo Estatuto como objeto sob jurisdição da corte. O presente trabalho tem por objetivo verificar se, diante das prerrogativas do Conselho de Segurança estabelecidas pelo Estatuto de Roma em relação ao crime de agressão, o Tribunal Penal Internacional tem garantido a sua atuação de forma autônoma e eficiente.

\section{Palavras Chave}

Direito Penal Internacional - Tribunal Penal Internacional - Conselho de Segurança Crime de agressão

\section{Abstract}

After the end of World War II, with the insurgency of the necessity to protect the basic rights inherent to the human being, the Universal Declaration of Human Rights (UDHR) was established and it came to enforce this protection to the so-called human rights. At the same time, the international organization which would be considered the one with the greatest global influence was created: the United Nations (UN), headed by its most powerful organ, the Security Council. However, due to the increasing number of acts against the humanity, it was necessary to guarantee these rights efficiently, in addition to only proclaim them. In this context, after five decades of the UDHR establishment, and based in its principles, a new branch of the international law emerged: the International Criminal Law - which was materialized by the institution of an important

\footnotetext{
${ }^{1}$ Acadêmica do $9^{\circ}$ semestre do curso de Direito (diurno) da Universidade Federal de Santa Maria (UFSM).
} 
judicial organ in 1998, the International Criminal Court. Although it represents a major breakthrough, the court is target of many discussions and critics since its birth, particularly with regard to the organ's autonomy in relation to the United Nations Security Council, and especially regarding to the crime of aggression which was enrolled by the Statute as an object of the court jurisdiction. This paper aims to verify if, on the Security Council prerogatives brought by the Rome Statute regarding the crime of aggression, the International Criminal Court has ensured its operations in an autonomous and efficient way.

\section{Keywords}

International Criminal Law - International Criminal Court - United Nations Security Council - Crime of aggression 


\section{Introdução}

Como dizia Bobbio (2004, p. 21), "haverá paz estável, uma paz que não tenha a guerra como alternativa, somente quando existirem cidadãos não mais apenas deste ou daquele Estado, mas do mundo". As palavras do brilhante jurista italiano ilustram um desafio lançado à humanidade desde a consolidação dos direitos do homem como positivados, declarados pela Organização das Nações Unida na Declaração Universal dos Direitos do Homem, em 1948, logo após a Segunda Guerra Mundial. Esta Carta, enquanto resposta às atrocidades cometidas durante a guerra pelo nazismo, surge como um conjunto de princípios e valores universais a serem respeitados por toda a comunidade internacional. Esta foi o passo inicial e o marco referencial do processo de internacionalização dos direitos humanos e de sua reconstrução, fazendo nascer o chamado Direito Internacional dos Direitos Humanos. Entretanto, e como bem assinala Seitenfus e Ventura (2006), não foi previsto instituto para o controle da aplicabilidade destas normas, o que se configurou como uma escassa eficácia da proteção dos direitos humanos.

Antes de mergulhar no assunto proposto por este trabalho, uma breve distinção entre o conceito de direitos humanos, direitos do homem e direitos fundamentais se mostra importante. Não poucas vezes se faz confusão entre os termos, logo, é de grande relevância diferenciá-los. Conforme leciona Galvão (2008), os chamados direitos do homem são de cunho jusnaturalista, possuindo sua origem no direito natural - e são, portanto, segundo Bobbio (2004), direitos históricos; assim, são aqueles direitos que nascem com o ser humano e são inerentes a ele, sem que estejam escritos em qualquer ordenamento jurídico nacional ou tratado internacional. Já os direitos fundamentais, por sua vez, são os direitos do homem positivados na Constituição de um país e, desta forma, estes são uma instituição de direito internacional constitucional. Por fim, ainda segundo Galvão (2008): "Direitos humanos, por sua vez, conotam aqueles direitos escritos/positivados em tratados e convenções internacionais específicos de direitos humanos, quer no plano global (ONU), quer nos contextos regionais (dentre os quais o interamericano)".

Assim, tendo em vista tais conceitos, verifica-se que o gênero de direitos protegidos pelo novo ramo do direito internacional que surge com a Declaração Universal dos Direitos do Homem é o dos direitos humanos, sendo assim classificado e 
estudado a partir desta importante convenção que veio a internacionalizar esses direitos após a sua já consagração em muitas Constituições nacionais.

A ideia de que os direitos humanos não devem apenas ser protegidos pelos Estados, mas também no âmbito da ordem internacional, foi o referencial para que fossem criados, bem como para que assim fossem criados também órgãos que garantissem esses direitos internacionalmente. Nas palavras de Bobbio (2004, p. 43) sobre a efetiva proteção destes direitos em nível internacional:

\begin{abstract}
Deve-se recordar que o mais forte argumento adotado pelos reacionários de todos os países contra os direitos do homem, particularmente contra os direitos sociais, não é a sua falta de fundamento, mas a sua inexeqüibilidade. Quando se trata de enuncialos, o acordo é obtido com relativa facilidade, independentemente do maior ou menor poder de convicção de seu fundamento absoluto; quando se trata de passar à ação, ainda que o fundamento seja inquestionável, começam as reservas e as oposições.
\end{abstract}

Nesse sentido, a fim de garantir que os direitos humanos fossem respeitados, e devido ao contexto de conflitos armados, genocídios e guerras enfrentadas por vários Estados, em 1998 - ou seja, decorrido razoável lapso temporal desde a DUDH -, foi criado pelo Estatuto de Roma o chamado Tribunal Penal Internacional (TPI). O TPI é uma corte de caráter e jurisdição internacional e permanente, diferente de outras cortes antecessoras a ela, e incumbida de julgar os indivíduos acusados pela prática dos crimes mais graves da humanidade, como os crimes de guerra, de genocídio e de agressão (Lewandowski, 2002), esses considerados crimes internacionais.

Todavia, desde o início de sua atuação, em 2002, é evidente que o tribunal vem enfrentando grandes dificuldades para alcançar os objetivos para os quais foi criado. Desde antes de seu estabelecimento, houve discussões sobre pontos de seu pré-projeto, como, por exemplo, a sua jurisdição internacional, que poderia vir a ferir a soberania dos Estados; ou os sujeitos que poderiam dar início a ação penal no tribunal; ou até mesmo sobre os crimes arrolados como da competência do órgão judicial. Em relação a este último ponto, a questão alvo de acirradas controvérsias é sobre a inclusão do chamado crime de agressão como delito de competência do TPI e sobre a sua definição, já que, considerando que o ato de agressão foi criado e definido pelo Conselho de Segurança da ONU, sua natureza é essencialmente política. Tal fato levaria, portanto, a uma ampla ingerência do Conselho na atuação do Tribunal Penal Internacional no que 
tange a este tipo de crime, prejudicando, assim, as premissas máximas do TPI enquanto órgão independente e autônomo e a atuação eficiente do mesmo.

Neste contexto, o presente trabalho pretende realizar uma análise sobre o crime de agressão e verificar, especificamente, as prerrogativas do Conselho de Segurança da ONU previstas pelo Estatuto de Roma do Tribunal Penal Internacional, a fim de concluir se a atuação da corte penal em questão estaria comprometida diante da ingerência do Conselho. Para isso, inicia-se o trabalho com um breve histórico do surgimento do Direito Internacional Penal e do TPI - com foco em comentários sobre sua jurisdição, - passando-se a um singelo capítulo sobre o Conselho de Segurança das Nações Unidas, e, finalmente, é alcançada a questão central deste artigo, com posterior conclusão do estudo.

\section{A criação do Direito Internacional Penal}

Não é de hoje que a ideia de se julgar indivíduos por crimes de gravíssima natureza existe. Estima-se que desde os anos antes de Cristo foram criados tribunais ad hoc para punir os responsáveis pelos delitos cometidos durante as guerras, principalmente na Grécia, ou até mesmo em um acordo celebrado entre o reino egípcio e o império dos Hititas, em 1280 a.C. (Oliveira, C. J. M., 2010). Entretanto, uma maior conscientização a nível mundial dos direitos comuns a todos os cidadãos começou a surgir após o fim da Primeira Guerra Mundial, ocorrida entre 1914 e 1918, na qual a batalha travada entre grandes potências mundiais da época resultou em imensuráveis e desastrosas perdas humanas. Nesse sentido, pode-se dizer que foram os anseios de uma sociedade internacional heterogênea, e não centralizada, que deram início a evolução histórica da jurisdição internacional penal, a fim de lutar contra a impunidade (Carvalho \& Araújo, 2008).

Nesse sentido, em 1920, começou a atuar a organização internacional chamada Liga das Nações, órgão antecessor a ONU, e que tinha por objetivo promover a cooperação, paz e segurança internacional, condenando agressões externas contra a integridade territorial e a independência política de seus membros (Colli Júnior, 2011). A Liga das Nações era formada pelos países vencedores da Primeira Guerra Mundial, e, apesar da assinatura de 44 Estados-membros da Liga, a organização não durou muito tempo e não alcançou seu objetivo de manutenção da paz e segurança internacionais, 
pois "as iniciativas não conseguiram dar frutos em uma época que valorizava excepcionalmente as questões de soberania estatal" (Cassesse, 2005, p. 4-5).

Alguns anos depois, o mundo, especialmente a Europa, já tomava direção rumo a mais uma grande crise, que mais tarde desembocaria em outra devastadora guerra. A Segunda Guerra Mundial eclodiu em 1939 e durou até o ano de 1945. Ainda que a sua antecessora - a Primeira Guerra Mundial - tenha sido denominada "a guerra para acabar com todas as guerras", aquela ultrapassou, assustadoramente, o número de vítimas e o nível de atrocidades cometidas na Grande Guerra, deixando uma estimativa de cerca de 50 e 60 milhões de mortos, e, como bem salientado por Cassesse (2005, p. 18), "os piores autores desses crimes, entre eles alguns ocupando posições de tomada de decisões, e seus principais executores, raramente foram levados a responder por seus delitos e, em conseqüência disso, não foram punidos".

O choque pelo conhecimento das atrocidades cometidas na Segunda Grande Guerra concretizou a efetiva preocupação com os direitos humanos. Nas palavras de Coelho (2007, p. 7159-7160): “É a partir de 1945 que a temática dos direitos humanos entra, de forma incisiva, na agenda dos Estados, que, perplexos com os acontecimentos ocorridos durante a guerra e com os julgamentos que a sucederam, passaram a destinar preocupação especial com a matéria".

Observou-se, então, que ao mesmo tempo em que a Organização das Nações Unidas era criada em 1945 para a promoção e facilitação da cooperação internacional nas mais diversas áreas, também foram estabelecidos vários tribunais ad hoc, ou "tribunais de exceção", criados de acordo com as necessidades do momento e dos casos específicos de desrespeito aos direitos humanos. Segundo leciona Brandão (2006):

Após a Segunda Guerra Mundial, o problema da vigência de um verdadeiro Direito Internacional Penal também passou a ser discutido pela comunidade internacional como decorrência da proteção dos Direitos Humanos. De fato, alicerçadas no Acordo de Londres, firmado em 8 de agosto de 1945, as quatro potências aliadas instituíram os Tribunais de Nuremberg e Tókio, com o fim de julgar os criminosos de guerra nazistas e japoneses. Esses Tribunais ad hoc receberam competência para julgar os autores de crimes contra a humanidade, os crimes contra a paz e os crimes de guerra, crimes estes que constituiriam um princípio do Direito Internacional Penal. No âmbito da competência recebida, determinaram a execução de 
sentenças por crimes internacionais, inclusive a execução de penas de morte.

Alguns dos tribunais de exceção tiveram maior importância e notoriedade no cenário internacional, inclusive por julgar criminosos de conflitos e guerras de larga escala e duradouras. É o caso do Tribunal de Nuremberg e do Tribunal de Tóquio, estabelecidos, respectivamente, nos anos de 1945 e 1946.

Devido ao surgimento destes tribunais ad hoc, defendia-se cada vez mais a criação de um tribunal permanente que tivesse jurisdição internacional e a competência para julgar crimes de gravíssima repercussão, como aqueles já haviam sido cometidos anteriormente nos conflitos. Um tribunal que pudesse investigar, processar, julgar e condenar criminosos, os quais, pelo motivo que fosse, não fossem julgados pelos tribunais nacionais, em forma de complemento à jurisdição dos Estados. Assim, em 1948, a ONU dá início aos estudos sobre o estabelecimento de um tribunal penal internacional, adotando, no mesmo ano, a Declaração Universal dos Direitos do Homem (DUDH) (Coelho, 2007), sobre a qual Bobbio (2004) afirma ter sido a solução atual para o problema do fundamento dos direitos humanos. Ainda segundo o jurista italiano (2004, p. 50):
A Declaração Universal contém em germe a síntese de um movimento dialético, que começa pela universalidade abstrata dos direitos naturais, transfigura-se na particularidade concreta dos direitos positivos, e termina na universalidade não mais abstrata, mas também ela concreta, dos direitos positivos universais.

Todavia, importa salientar que, durante o período da Guerra Fria, o projeto de criação de um tribunal penal que tivesse jurisdição internacional ficou suspenso, já que a disputa ideológica impedia que fosse criado um consenso sobre quais valores deveriam ser considerados fundamentais e garantidos pela atuação de um novo juízo a ser estabelecido. Conforme explica com propriedade Bassiouni, citado por (Carvalho \& Araújo, 2008):

Em 1950, enquanto o Tribunal Penal estava apenas no plano teórico, os pensamentos das potências mundiais eram os seguintes: a União Soviética pensava que sua soberania seria afetada pelo estabelecimento de um tribunal; os Estados Unidos não estavam dispostos a aceitar tal corte no apogeu da Guerra Fria; a França exprimia seu suporte ao estabelecimento de um Tribunal Penal Internacional permanente, mas não utilizou sua influência para acelerar o processo; e o Reino Unido achava a idéia prematura. 
Cabe notar que, ainda que tenha havido uma paralisação dos trabalhos para a criação da Corte Penal Internacional, a discussão sobre os direitos humanos não deixou de avançar. Um exemplo disso foram os diversos pactos que contribuíram para o processo de universalização destes direitos, como o Pacto Internacional dos Direitos Civis e Políticos, e o Pacto Internacional dos Direitos Econômicos, Sociais e Culturais, ambos de 1966 (Coelho, 2007).

Embalados pela causa, no ano de 1989, no final da Guerra Fria, muitos países latinos, liderados por Trinidad e Tobago, ressuscitaram a ideia de criação de um tribunal internacional. Entretanto, em que pese tal progresso neste ramo do direito internacional, a década de 1990 exibe o retorno das barbáries, dos nacionalismos e do desrespeito aos direitos das minorias étnicas, motivados, principalmente, pelo fim do artificialismo que regrou a Europa nas últimas décadas (Coelho, 2007).

Assim, tomando em conta a reivindicação de vários Estados, e diante da crescente violação dos direitos humanos, a Organização das Nações Unidas, munida de competência para tal, e através do Conselho de Segurança, agiu para que fossem punidos os violadores de gravíssimas normas do Direito Humanitário (Carvalho \& Araújo, 2008). Constituíram-se, dessa forma, mais dois tribunais de exceção após o de Nuremberg e Tóquio: o Tribunal para a ex-Iugoslávia (TPII) e o de Ruanda (TPR), em 1993 e 1994, respectivamente, cujas atuações, todavia, não foram suficientes para a aplicação da justiça efetiva para as vítimas das atrocidades cometidas nos dois países. Mesmo diante disso, não se pode de todo desmerecer a iniciativa e os resultados destes dois juízos de exceção, porquanto ambos consistiram em uma motivação para a criação, finalmente, de um tribunal penal internacional. Nas palavras de Cassesse (2007, p. 1617):

Embora limitados temporal e geograficamente aos conflitos na Iugoslávia e em Ruanda, os êxitos Gerais do TPII e do TPR, respectivamente, deram um estímulo final ao surgimento do TPI, um órgão de alcance jurisdicional global e, portanto, potencialmente capaz de responder a violações que ocorressem em qualquer parte. Além disso, uma importância simbólica havia surgido a partir dessas experiências em termos de legado moral, e muita jurisprudência acumulada com relação à interpretação dos delitos puníveis segundo o novo Estatuto. Ambos podem ser tomados como base por aqueles que buscassem um sistema de justiça penal internacional permanente, eficaz e praticamente isento. 
Dessa forma, percebeu-se que a criação de tribunais de exceção para processamento e julgamento dos chamados crimes contra a humanidade, posteriormente definidos pelo Estatuto de Roma, além de não alcançar por completo os objetivos que eram propostos no momento da criação, exigiam um alto custo para seu estabelecimento e manutenção.

Então, tendo em vista estes argumentos, e diante de um maior clamor para proteção dos direitos humanos frente à inércia ou ineficácia da atuação nacional na segurança destes novos direitos, em 17 de julho de 1998, através do Tratado de Roma, era criado o Tribunal Penal Internacional, órgão cujo nascimento consolida, de forma definitiva, o ramo do direito internacional penal.

Diante deste histórico, não é possível afirmar a data exata em que surge o direito internacional penal. $\mathrm{O}$ que se pode afirmar é que ele nasce com o objetivo de reprimir eficazmente determinadas condutas para cuja persecução criminal o Estado não se mostrasse eficiente (Clementino, 2010), consubstancia-se na criação dos diversos tribunais penais ad hoc e alcança o seu objetivo maior com o estabelecimento do TPI que, por sua vez, consolida um juízo internacional para o processamento e julgamento dos crimes que atentem contra os direitos humanos. Conclui-se esta parte do trabalho com o ensinamento de Cassesse (2005, p. 18), em alusão a Bassiouni:

\footnotetext{
Nos setenta e cinco anos que se seguiram a 1919, as maiores potências do mundo, mesmo que tenham sido seletivas na instalação de organismos ad hoc para investigar determinados crimes internacionais, reconheceram progressivamente as aspirações da sociedade civil internacional com relação ao estabelecimento de um sistema de justiça penal internacional.
}

\section{O Tribunall Penal Internacional: Breves comentários sobre sua jurisdição}

O Tratado ou Estatuto de Roma, que prevê a criação do Tribunal Penal Internacional, foi aprovado em 17 de julho de 1998, em Roma, Itália, e no último dia da Conferência Diplomática de Superpotências das Nações Unidas, por uma maioria de 120 votos a favor, 7em contrário (sendo eles da China, dos Estados Unidos, das Filipinas, da Índia, de Israel, do Sri Lanka e da Turquia) e 21 abstenções, entre eles a de vários países árabes e islâmicos (Coelho, 2007). Interessante notar que, com essas abstenções e votos contrários, mais da metade da população mundial ficou fora do alcance do TPI. 
Percebe-se, portanto, que a aprovação para a criação do Corte Penal Internacional não se deu de forma unânime. Ainda assim, a aprovação do tratado constituiu um grande passo para a aplicação e proteção do direito internacional humanitário. Sobre tal fato, aduz Cassesse (2005, p. 19):

Não obstante, é a promulgação do Estatuto do TPI que representa o ápice da institucionalização e da universalização das medidas para essa aplicação [do direito internacional humanitário]. O órgão cumpre os propósitos de uma justiça simbólica e, com o requisito do apoio dos Estados, também será capaz de proporcionar uma solução judicial eficaz que pode distribuir, razoavelmente, pelo menos, alguma justiça eqüitativa e restaurativa.

Ainda segundo este autor, o estatuto "cristaliza todo o corpo de direito que foi surgindo gradativamente durante os últimos cinqüenta anos na comunidade internacional, nessa área particularmente problemática" (Cassesse, 2005, p. 3). Em que pese ter sido criado no ano de 1998, apenas quatro anos mais tarde, em 2002, a corte passou a atuar efetivamente, quando se estabeleceu sua sede em Haia, nos Países Baixos.

A proposta do TPI é de ser uma corte permanente com jurisdição internacional e com o objetivo de investigar e trazer a julgamento pessoas físicas - e não Estados, incumbência esta da Corte Internacional de Justiça, órgão da ONU - que tenham cometido os chamados crimes internacionais, classificados como de natureza gravíssima e trazidos entre os primeiros artigos do Estatuto de Roma. São esses os crimes de genocídio, crimes de guerra, crimes contra a humanidade e os crimes de agressão. Quanto a estas espécies de delito, assinalam Carvalho e Araújo (2008):

Esta categoria é denominada "crimes internacionais" ou "crimes
contra a paz e a segurança da humanidade" e possui crimes que se
distinguem de outros por possuírem certo aspecto coletivo, realmente
público. Trata-se, segundo Hervé Ascensio, de uma criminalidade de
sistema e este sistema é freqüentemente um aparelho do Estado ou de
tipo estatal. Os indivíduos processados penalmente o são devido ao
fato de serem uma engrenagem deste sistema criminal, ou devido ao
fato de exercerem sua função e utilizarem os meios assim colocados a
sua disposição para fins criminosos.

Tendo em vista que proposta deste trabalho se restringe ao estudo do crime de agressão, não cabe aqui tratar e discursar acerca de cada um dos crimes e suas características, inclusive pelo excesso de informações superficiais que se pode trazer ao estudo. Por isso, em seguida tratar-se-á do crime de agressão, objeto do artigo, enquanto 
que, no presente capítulo, é importante tecer alguns comentários sobre a jurisdição do TPI os quais contribuirão para um melhor entendimento do estudo mais adiante.

Conforme já referido, a corte em questão possui jurisdição internacional, ou seja, não se constitui em uma jurisdição estrangeira (Câmara dos Deputados, 2000), que viria a intervir na atuação e nos sistemas penais dos Estados relativamente ao processamento e julgamento de seus nacionais. Assim, há clara distinção entre a chamada jurisdição universal ou global, e a jurisdição internacional, que é a da corte. Aquela se constitui, no ensinamento de Jardim (2000), na possibilidade da jurisdição interna poder julgar crimes de guerra ou crimes contra a humanidade ocorridos nos territórios de outros países; trata-se aqui, portanto, da questão da extraterritorialidade do direito penal, a qual é admitida no direito brasileiro em certos casos, como, por exemplo, o local do crime possuir regime internacional (Câmara dos Deputados, 2000).

Em que pese à ideia de um sistema de justiça penal internacional - na qual os países abrem mão de serem sujeitos máximos do direito internacional, - seja uma realidade, as noções de soberania estatal ainda se encontram bastante fortalecidas. Sobre este ponto, discursa Abreu (2004):

Tem-se firmado, no entanto, uma nova tendência no sentido de se permitir julgamentos de nacionais além das fronteiras dos seus Estados de origem. Isso se deve ao reconhecimento de que determinados atos criminosos extrapolam o interesse de determinado Estado, atingindo proporções supranacionais.

Tanto é verdade que o TPI é dotado de jurisdição internacional, a qual, diferentemente da acima esposada, segue algumas premissas bem importantes consagradas, inclusive, pelo Estatuto de Roma. Dentre eles, destaca-se o princípio da complementariedade e o princípio do respeito à soberania dos Estados.

Relativamente à ideia de soberania, este é um ponto que direito internacional em geral vem enfrentando desde os seus primórdios. Isto porque o instituto da soberania do Estado, ainda que venha sofrendo o que Ferrajoli (2002) chama de crise de legitimação, ainda constitui-se em paradigma, e não se mostra um conceito que se extinguirá com tanta facilidade. Por este motivo, o TPI possui como premissa o respeito à soberania estatal, o que nada mais é do que se admitir como um órgão subsidiário, que apenas agirá diante da inércia proposital ou da incapacidade da atuação do Estado através de seu sistema penal interno, independente de qual seja. 
Todavia, ainda que o princípio da soberania estatal se mostre elemento norteador da corte penal, é inegável que esta necessita da cooperação dos Estados para atingir seu fim maior. Isto porque o TPI não possui polícia ou exércitos próprios, dependendo então destas instituições nacionais para investigar, processar e julgar seus réus de forma eficiente e justa.

Nesse contexto, novas palavras de Abreu (2004, p. 5):

Dentro dessa nova ordem, a jurisdição doméstica não atende os anseios da comunidade internacional, porquanto a soberania, nos dias atuais, revela-se por meio de ações praticadas em conjunto, com vista à obtenção de finalidades comuns. Reclama-se dos Estados uma intensa participação nos assuntos atinentes ao sistema internacional.

O princípio da complementariedade, o qual guia a atuação do TPI, vem a se somar à ideia de respeito à soberania dos Estados. De acordo com Sabóia (2000), seu objetivo é assegurar que a corte exerça a função que lhe é atribuída sem interferir indevidamente nos sistemas penais nacionais, os quais têm garantida a incumbência de responsabilidade primária pela investigação e processamento dos crimes. Apenas se o Estado não quiser ou não puder julgar seu nacional acusado da prática dos crimes elencados pelo estatuto, o tribunal exercerá sua jurisdição.

Nesta monta, assegura Gabriela Werner Oliveira (2010, p. 41):

Decorre daí que o Tribunal te sua jurisdição bem delimitada pelo Estatuto, de tal modo que a tentar manter um equilíbrio, preservando o princípio d a soberania estatal, mas também levando em consideração as conjunturas atuais da sociedade internacional, onde a violação dos direitos humanos - ao menos teoricamente - é inadmissível.

Algumas questões sobre a jurisdição do TPI ainda ensejam acirrados debates, tais como a possibilidade de o tribunal julgar nacionais de um Estado que não tenha ratificado o Estatuto de Roma ou não reconheça a jurisdição da corte. Segundo o tratado, o órgão judicial apenas tem competência para julgar nacionais dos estados signatários ou dos que reconheçam o TPI como órgão internacional para tal, ou para julgar aqueles que cometerem crimes nos territórios destes países. Um recente caso que levantou grande polêmica acerca desta questão é o do presidente do Sudão, Oman alBashir, acusado pelo TPI por prática de crimes de guerra e contra a humanidade na região de Darfur (Oliveira, G. W., 2010). O caso vem desafiando o TPI, uma vez que o Sudão não é signatário do Tratado de Roma e possui o apoio dos países da Liga Árabe, 
além da Rússia e da China, também não signatários. Importante salientar, neste aspecto, que, nos casos em que o Conselho de Segurança remete o caso à corte, tais condições não necessitam ser respeitadas.

Mesmo diante das inúmeras discussões acerca das complexas questões sobre o direito internacional penal e a própria corte, o que se tem por certo é que o TPI, no que diz respeito a sua jurisdição e competência para atuar, possui características e regras de ação bem definidas pelo seu tratado criador. Tal fato contribui para que os Estados, principalmente aqueles mais relutantes em aceitar a realidade do Tribunal Penal Internacional, reconheçam-no, deem-lhe credibilidade e passem a cooperar com o órgão, facilitando sua atuação e o aperfeiçoando na proteção internacional dos direitos humanos.

\section{O Conselho de Segurança da Organização das Nações Unidas}

Anos antes da criação da Corte Penal Internacional, e logo após o término da Segunda Guerra Mundial, mostrava-se necessário restabelecer as relações amistosas entre os países do globo, principalmente entre as grandes potências envolvidas nas duas grandes guerras do século XX, uma vez que a Sociedade das Nações (SDN), ou simplesmente Liga das Nações havia falhado em seu objetivo maior de garantir a segurança e a cooperação internacional, apesar de recolher pequenas vitórias (Seitenfus \& Ventura, 2006).

Nesse sentido, a fim de solucionar os problemas sociais, econômicos e humanitários que atingiam as nações do mundo, em 1945, na cidade de São Francisco, nos EUA, era aprovada a Carta das Nações Unidas, que estabelecia o organismo que até hoje ocupa a posição de mais importante organização internacional do mundo: a Organização das Nações Unidas. Para uma atuação mais eficiente, a ONU, apesar de seu desmembramento complexo, é estruturada em três principais órgãos: a Assembleia Geral; o Secretariado, de função administrativa; e o Conselho de Segurança, sobre o qual cabe se ater neste trabalho.

O Conselho de Segurança da ONU pode ser considerado o órgão mais poderoso do organismo, haja vista ter por incumbência, segundo o art. 24 da Carta das Nações Unidas, a manutenção da paz, agindo nos casos de ameaça contra a paz, ruptura da paz ou ato de agressão. A decisão sobre como conter as ameaças ou efetivas agressões é 
tarefa do Conselho, o qual pode definir e executar sanções militares contra os Estados responsáveis, utilizando-se de forças armadas à sua disposição pelos países membros da ONU, mediante acordo (Seitenfus \& Ventura, 2006). Cabe ressaltar que as decisões do Conselho muitas vezes possuem força de lei, sendo obrigatória para os todos os Estados membros da ONU.

O órgão é composto por quinze membros, sendo cinco deles permanentes (EUA, Rússia, França, Inglaterra e China) e dez temporários; entre os componentes permanentes prevalece a regra da unanimidade no que diz respeito à tomada de decisões. Também, em decorrência, há o chamado poder de veto por parte dos cinco países, podendo estes bloquear qualquer decisão do Conselho. Diante disso, é incontestável o poder dado aos cinco membros permanentes, os quais, não coincidentemente, constituem os países considerados vencedores da Segunda Guerra Mundial, além de serem os únicos Estados nucleares declarados, conforme ressalta Gabriela Oliveira (2010). Ainda, segundo a autora (2010, p. 19):

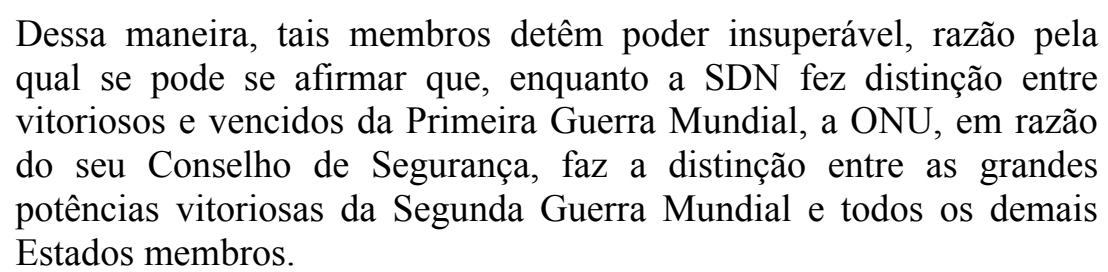

Entretanto, por conta da Guerra Fria, na qual houve o embate entre as ideologias americana e soviética, o órgão em questão teve suas atividades em grande parte paralisadas, haja vista que os dois pólos se utilizaram de seu poder de forma abusiva. Como bem analisam Seitenfus e Ventura (2006, p. 110):

Diante da impossibilidade de consenso entre as potências portadoras de ideologias diversas, a regra da unanimidade entre os membros permanentes foi responsável pela paralisia que predominou nesta instância durante a Guerra Fria. Indubitável também a hegemonia dos chamados cinco grandes sobre os demais membros, em franca dissonância com o artigo $2^{\circ}$ da própria Carta das Nações Unidas, que prescreve a igualdade entre os Estados, princípio fundamental do direito internacional.

Portanto, frente a tais conclusões, fica evidente que o Conselho de Segurança da ONU se configura como um órgão político e que as decisões por ele tomadas, mais especificamente no que tange a produção normativa de caráter impositivo que caracteriza as Resoluções dele provenientes, apresentam um alto grau político 
(Seitenfus, 2005). Dessa forma, existe um claro embate entre o político e o jurídico no âmbito do órgão em comento. Há quem diga que os aspectos políticos do Conselho seriam sua força motriz e que o direito, por sua vez, estaria esvaziado em várias questões, como o uso da força, "críticas essas relacionadas à própria natureza do direito internacional" (Oliveira, G. W., 2010, p. 20). Na contramão, afirma-se que as decisões políticas do Conselho são pautadas pelo direito internacional, argumentando que o órgão foi estabelecido pela Carta das Nações Unidas, tratado multilateral e produto do direito internacional, sendo, portanto, "seus poderes fundados e limitados pelo Direito" (Viotti, 2004, p. 19-20).

Atualmente, na medida em que vem crescendo o número de casos analisados, debatidos e decididos pelo órgão mais poderoso da Organização das Nações Unidas, cada vez mais se discute a chamada reforma do Conselho de Segurança, defendida por vários países, dentre eles o Brasil. Argumenta-se que, através de uma reformulação do órgão, seria possível torna-lo mais eficiente e menos parcial. Entretanto, discute-se mais sobre a composição do Conselho do que sobre sua eficiência, restando inócua qualquer tentativa de apreciar efetivamente a reforma desejada (Conceição, 2009) - haja vista que a maioria delas tem como efeito posterior a diminuição da eficiência de atuação do órgão. Assim, assinala Mont'Alverne (2010, p. 03):

O Conselho de Segurança se ressente de um enorme déficit de credibilidade sobretudo após a guerra do Iraque; fazendo-se necessário reconstituí-la. A reforma é salutar, mas não deve ser um eufemismo que mascara uma diminuição da eficácia do Conselho de Segurança. Contudo, é preciso reconhecer que não é fácil determinar ou definir as modificações necessárias a fim de tornar o Conselho de Segurança mais eficiente ainda que a reforma pareça indispensável para a sobrevivência da instituição.

Mesmo diante do clamor pela reforma e das lacunas presentes na credibilidade do Conselho de Segurança da ONU as quais minam sua autoridade (Mont'Alverne, 2010), é tolo negar que tal órgão possui importante papel na condução das relações internacionais atuais, bem como atuação destacável para a justiça penal internacional com a criação dos tribunais de exceção para a antiga Iugoslávia e de Ruanda - passos iniciais para o estabelecimento do Tribunal Penal Internacional, cujas prerrogativas também podem ser atribuídas ao Conselho (Oliveira, G. W., 2010). 


\title{
A relação do Tribunal Penal Internacional e do Conselho de Segurança quanto ao crime de agressão
}

Desde antes mesmo de sua criação, o Tribunal Penal Internacional foi alvo de discussão, principalmente quanto aos aspectos políticos e jurídicos que envolviam a atuação de uma corte penal de jurisdição internacional. Os Estados, durante os trabalhos que posteriormente dariam origem ao tribunal, tinham suas opiniões divididas nos vários temas abordados durante as sessões. Isto porque, apesar da eminente necessidade de estabelecer uma corte permanente, o direito internacional, em seus mais variados ramos, ainda era recente e gerava muitos receios. Na visão de Kirsch, Q.C. e Oosterveld (2005, p. 58):

\begin{abstract}
Nos últimos anos de negociações preparatórias, diversas questões haviam sido trazidas à tona e discutidas, gerando um conjunto enorme de propostas conflitantes. As negociações preparatórias também haviam revelado as profundas divisões entre as posições de cada país, a complexidade das questões que se apresentavam, e as muitas formas com que o projeto do TPI tocava questões delicadas com relação à soberania. Sendo assim, além de razões para esperança, havia muitas dúvidas sobre a viabilidade de solução dessas inúmeras questões durante o tempo destinado à conferência.
\end{abstract}

De qualquer forma, independente dos receios e dúvidas dos Estados antes e depois da criação da corte em comento, o Tribunal Penal Internacional surge como alternativa aos tribunais ad hoc e como órgão autônomo, independente e imparcial, conforme suas premissas (Oliveira, G. W., 2010).

Em que pese serem inúmeros os aspectos que geraram - e geram - polêmica sobre o Estatuto de Roma e o Tribunal Penal Internacional, uma das questões que merece maior destaque é a do relacionamento do Conselho de Segurança da ONU com a corte penal. Ainda que se desejasse um tribunal independente e autônomo, à época, o órgão das Nações Unidas já possuía a relevância e força que tem hoje e, tendo em vista a sua função de manter a paz e a segurança internacionais, possíveis ações, processos ou julgamentos de criminosos de diversas nacionalidades pelo órgão penal poderiam levar o Conselho de Segurança a agir conforme sua competência. Assim, principalmente por iniciativa dos membros permanentes do Conselho (com exceção do Reino Unido), o papel do referido órgão junto ao Tribunal foi amplamente debatida. Lecionam Kirsch, Q.C. e Robinson (2005, p. 25): 
Esses Estados tinham a expectativa de que o Conselho exercesse uma função central, tanto encaminhando questões ao Tribunal quanto filtrando ou obstruindo casos antes que chegassem a ele. Também expressavam preocupação com a jurisdição automática e a proposta de poder o promotor propor a ação penal. Por fim, não queriam que os crimes de agressão ou uso de armas nucleares fossem incluídos no Estatuto.

Diante disso, percebe-se que as propostas apresentadas e defendidas pelos Estados permanentes do Conselho visavam diminuir a independência da corte, imputando considerável controle por parte do órgão da ONU. Muitos países, todavia, defendiam a ideia contrária: por exemplo, a maioria deles estava comprometida com a inclusão do crime (ou ato) de agressão no estatuto, e outros se opunham fortemente a qualquer função a ser cumprida pelo Conselho em relação à atuação do Tribunal (Kirsch et al, 2005). É sobre a polêmica da configuração do crime de agressão, presente na convenção de Roma, que o presente trabalho pretende discorrer.

Primeiramente, tem-se que, durante os debates para a definição dos crimes que seriam objeto de processamento e julgamento pelo TPI, não havia consenso sobre o conceito desta espécie penal, além dela possuir natureza essencialmente política (Oliveira, G. W., 2010). O que se tinha, até então, era a definição já dada ao tipo penal de acordo com a Resolução XXIX da ONU, datada do ano de 1974, que dispõe em seu artigo 1": "Agressão é o uso da força armada por um Estado contra a soberania, integridade territorial e independência política de outro Estado, ou em qualquer outra maneira inconsistente com a Carta das Nações Unidas, conforme o disposto nessa definição".

Ainda, o artigo $2^{\circ}$ da Resolução aduz que o uso de força armada por um Estado, em desobediência ao posto na Carta das Nações Unidas, constitui, a priori, ato de agressão, ainda que o Conselho de Segurança possa considerar que esta determinação não se justifica face à uma análise das circunstâncias ou consequências do fato quando estas se mostram de menor gravidade. Neste mesmo sentido, o artigo 39 da Carta da ONU escreve:

O Conselho de Segurança determinará a existência de qualquer ameaça à paz, ruptura da paz ou acto de agressão e fará recomendações ou decidirá que medidas deverão ser tomadas de acordo com os artigos $41 .^{\circ}$ e $42 .^{\circ}$, a fim de manter ou restabelecer a paz e a segurança internacionais. 
Interessante ressaltar que o conceito do crime de agressão apenas foi definido, conforme já referido, em 1974, o que remete ao fato de que os tribunais de exceção criados pelo Conselho antes dessa data, quais sejam, os Tribunais de Nuremberg, em 1945, e o de Tóquio, em 1946, foram estabelecidos para julgar atos de agressão, sem que, contudo, houvesse conceito consolidado para a chamada agressão.

Assim, vê-se o poder do Conselho sobre a caracterização e a determinação de um crime de agressão, mesmo após a edição da Resolução que o define. E é devido principalmente à discricionariedade do órgão da ONU em relação à agressão que houve a divisão de opinião entre os Estados sobre a entrada ou não do crime em questão no rol de competências do TPI. Para alguns, o artigo 39 da Carta era invocado alegando-se que apenas, e em qualquer situação, o Conselho deveria determinar a existência do ato de agressão; por outro lado, outros acreditavam que os demais órgãos da ONU, como a Assembleia Geral ou a Corte Internacional de Justiça, poderiam fazer este julgamento (Oliveira, G. W., 2010), relativizando-se o dispositivo.

Em relação à definição do crime de agressão, Cançado Trindade assevera sobre a opinião do professor Raymond Aron (2002, p. 254):

Com o mesmo ceticismo encarava, há duas décadas, os esforços das Nações Unidas no sentido de formular uma definição de agressão. Aqui o tempo veio dar razão a Aron. EM 1974, após vários anos de trabalho na área, foi adotada, pela Assembléia Geral da ONU, uma Definição da Agressão. Conforme previa Aron, a Definição limitou-se a um conceito restrito de agressão pelo uso da "força armada" em violação da soberania do Estado territorial (artigo 1). Mas como a Definição adotada e a enumeração dos atos de agressão (artigo 3 ) não são exaustivos, cabe ao Conselho de Segurança (artigo 4) a faculdade de determinar quaisquer outros atos que porventura possam constituir agressão conforme os dispositivos da Carta da ONU.

Ainda quanto à diversidade de opiniões sobre esta influência do Conselho em relação à atuação do TPI, Petry, citado por Gabriela Oliveira (2010, p. 50), afirma que “a jurisdição do TPI deve ser limitada apenas aos casos em que o Conselho de Segurança falha em agir, tendo em vista o caráter político deste órgão, que pode resultar em nenhuma ação". Em contrapartida, Jacobs, também referido pela autora, infere que não se pode presumir que o órgão da ONU e o Tribunal possuam objetivos divergentes, uma vez que ambos exercem funções para a manutenção da paz e segurança internacionais (Oliveira, G. W., 2010). 
Dando continuidade aos trabalhos de aperfeiçoamento do Estatuto de Roma e, consequentemente, do Tribunal Penal Internacional, a Conferência de Revisão do Estatuto de Roma do Tribunal Penal Internacional foi realizada e concluída em meados do ano de 2010. Referida conferência aprovou, dentre outras questões que poderiam contribuir para uma mais eficiente atuação do Tribunal, a relevante Resolução $\mathrm{n}^{0}$ 6, inserindo no tratado os artigos $8^{\circ}$ bis, 15 bis e 15 ter, os quais trazem, respectivamente, um conceito sobre o crime de agressão; o exercício da jurisdição do TPI sobre o crime em questão por iniciativa de um Estado ou pelo próprio Promotor; e o exercício da jurisdição sobre o crime de agressão por meio de remessa ao Conselho de Segurança

Com relação ao art. 15 bis da nova Resolução, Gabriela Oliveira aponta (2010, p. 52):

Importa salientar aqui, os parágrafos $6^{\circ}, 7$ e $8^{\circ}$ que fazem referência ao Conselho de Segurança. De acordo com eles, caso o Promotor conclua que há base razoável para conduzir uma investigação com relação a um crime de agressão, deverá verificar se o Conselho determinou que um ato de agressão foi cometido pelo Estado em questão,, notificando o Secretário Geral da ONU. Se o Conselho de Segurança fez tal determinação, o Promotor poderá conduzir uma investigação acerca desse crime. Entretanto, se o Conselho não fez tal determinação, o Promotor poderá realizar as investigações, desde que autorizado pelo Juízo de Instrução do TPI de acordo com o art. 15 e, ressalta-se, se o Conselho de Segurança não tiver decidido, nos termos do artigo 16.

Portanto, observa-se que, dada esta Resolução, alguns dispositivos do Estatuto receberam complementos e, como ponto mais importante, uma definição própria para o crime de agressão finalmente foi trazida. Todavia, os trabalhos concluídos pela Conferência de Revisão do Estatuto de Roma do Tribunal Penal Internacional não fizeram mais que desdobrar o que já vinha previsto no Estatuto de Roma. Desta forma, não houve significativa modificação na relação entre o TPI e o Conselho de Segurança, possuindo este, ainda, as mesmas prerrogativas concedidas pelo texto do tratado.

\section{Conclusão}

O direito internacional penal, nascido da necessidade de se dar efetiva proteção internacional aos direitos humanos declarados na DUDH, enfrentou, desde sempre, debates e críticas por parte dos Estados, o que se constitui, verdadeiramente, na 
complexa, porém estreita, relação entre o político e o jurídico no ramo do direito internacional.

Neste aspecto, relativamente ao Tribunal Penal Internacional, o ponto crucial posa sobre as atribuições trazidas pelo Estatuto de Roma ao Conselho de Segurança da ONU, as quais concedem certa ingerência deste órgão sobre aquele no que tange o seu modus operandi. Destaca-se, aí, a polêmica sobre o crime de agressão analisado, delito penal arrolado como crime de competência do TPI, e que, nos termos de dispositivos do Estatuto, invoca a atuação e controle pelo Conselho junto ao tribunal.

Entretanto, diante do estudo realizado ao longo do presente trabalho, o que se vê é que, ainda que o Conselho possa influenciar nos trabalhos da corte, não se pode dizer que a relação entre as duas instituições seja de dependência ou subordinação, uma vez que, ao trata-la desta forma, o maior e mais nobre objetivo do Tribunal Penal Internacional estaria sendo desconsiderado: o de processar e julgar, de forma independente e justa, os indivíduos acusados da prática dos crimes mais graves contra a humanidade. Assim, nas palavras de Coelho (2007, p. 7171):

\begin{abstract}
As normas do Estatuto reforçam a promoção e a defesa dos direitos humanos, pois criam mais uma instância apta a conhecer e punir as violações perpetradas. O Tribunal surge, então, como um instrumento de proteção dos direitos humanos, coroando os esforços de todos os estudiosos que sempre sonharam com uma instituição independente e descompromissada apta a julgar os delitos que de forma mais cruel afetam o ser humano.
\end{abstract}

Nesse particular, ressalta-se que o Tribunal Penal Internacional não foi criado e nem é pertencente ou vinculado a ONU e, por óbvio, ao Conselho de Segurança. Entretanto, a relação de cooperação - como pode assim ser chamada - entre os dois é clara e de grande importância, não estando consubstanciada apenas pelas previsões trazidas pelo Estatuto de Roma, mas também pela aprovação da Resolução 58/79 da Assembleia Geral da ONU, que foi definida como o acordo sobre a relação entre o TPI e a organização (Oliveira, G. W., 2010), firmando, de forma definitiva, a parceria de tão relevante importância entre estas duas instituições.

Além disso, frisa-se que, para que o sistema penal internacional atue de forma efetiva, buscando a plena realização da justiça, é necessária uma cooperação internacional de larga escala, o que envolve tanto os Estados - o que vai além da simples assinatura e ratificação do Estatuto de Roma - quanto os organismos 
internacionais e demais sujeitos do direito internacional. Isto porque, conforme bem ressalta Gabriela Oliveira (2010), no que tange aos conflitos internacionais, a forma de atuação do órgão competente para o julgamento não se apresenta como a das jurisdições nacionais, sendo bem mais complexo do que a simples análise de culpa e inocência; é necessário que haja, além do reconhecimento e do consenso sobre o papel do TPI, uma consciência global sobre a importância da proteção dos direitos humanos. Apenas assim será possível desfazer a ideia de utopia da manutenção da paz e segurança internacionais.

Finalmente, em que pese o direito internacional, na fase em que se encontra, e o próprio Tribunal Penal Internacional enfrentarem inúmeros desafios, principalmente no que diz respeito a paradigmas e dogmas da política como a ideia imutável de soberania dos Estados, o avanço alcançado até aqui aponta para resultados de sucesso e atingimento dos objetivos do ramo e do órgão. E, acredita-se que, diante do contexto atual, o sistema penal internacional, através de uma soma de interesses, tende a se fortalecer e cumprir com os objetivos propostos, garantindo justiça e combatendo a impunidade a nível internacional. 


\section{Referências}

ABREU, Marcelo Luís. Uma análise do Tribunal Penal Internacional e da sua efetividade perante a Constituição brasileira. 2004. Disponível em:

$<$ http://www.direitoufba.net/artigos/artigo011.doc> . Acesso em: 28 nov. 2011.

ACCIOLY, Hildebrando; SILVA, G. E. do Nascimento e; CASELLA, Paulo Borba. Manual de Direito Internacional Público. 17ª ed. São Paulo: Saraiva, 2009.

BASSIOUNI, Mahmoud Cherif. Chapitre 54: L'Expérience dês Prémières Jurisdictions Pénales Internationales. In: ASCENSIO, Hervé; DECAUX, Emmanuel; PELLET, Alain. (Sous la direction de) Droit international penal Paris: A. Pedone, 2000. p. 635-659

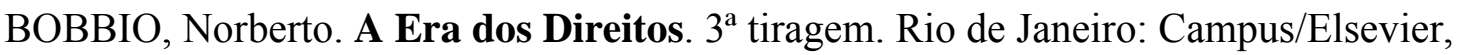
2004.

BRANDÃO, Renata Costa Silva. Tribunal Penal Internacional: uma nova realidade do Direito Penal Internacional para a garantia da segurança dos Direitos Humanos. 2006. 140f. Dissertação (Mestrado em Direito) - Universidade Gama Filho. Disponível em:

$<$ http://www.dhnet.org.br/direitos/sip/tpi/a_pdf/brandao_tpi_nova_realidade_dp.pdf $>$ Acesso em: 26 nov. 2011.

CÂMARA DOS DEPUTADOS. Comissão de Direitos Humanos. O que é o Tribunal Penal Internacional. Poder Legislativo, Brasília, DF, fev. 2000. Disponível em: http://www.dhnet.org.br/dados/cartilhas/dh/tpi/cartilha_tpi.htm. Acesso em: 28 nov. 2011.

CARVALHO, Luiza Starling; ARAÚJO, Priscilla Clementino. O Tribunal Penal Internacional e a consagração do princípio da responsabilidade penal internacional individual. Revista Eletrônica de Direito Internacional (CEDIN). 2008, v. 2. Disponível em:

$<$ http://www.cedin.com.br/revistaeletronica/artigos/Luiza\%20e\%20Priscilla\%20DH.pdf >. Acesso em: 28 nov. 2011.

CASSESSE, Antonio. De Nuremberg a Roma: dos Tribunais Militares Internacionais ao Tribunal Penal Internacional. In: AMBOS, K.; CARVALHO, Salo de.(Org.). O Direito Penal no Estatuto de Roma: Leituras sobre os Fundamentos e a Aplicabilidade do Tribunal Penal Internacional. Rio de Janeiro: Lumen Juris, 2005. p. 03-20.

CLEMENTINO, Marco Bruno Miranda. A culpabilidade no direito penal internacional. Revista CEJ. Brasília, Ano XIV, n. 51, out./dez. 2010, p. 51-65. Disponível em: < 
http://www2.cjf.jus.br/ojs2/index.php/cej/article/viewFile/1365/1384>. Acesso em: 28 nov. 2011.

COELHO, Sérgio Reis. A Teoria dos Direitos Humanos e a Jurisdição Penal Internacional: Uma análise de seus fundamentos históricos, filosóficos e de sua interrelação. In: XVI CONGRESSO NACIONAL CONPEDI, 2007, Belo Horizonte. Anais eletrônicos. Disponível em:

$<$ http://www.dhnet.org.br/direitos/sip/textos/a_pdf/coelho_teoria_dh_juris_penal.pdf $>$. Acesso em: 28 nov. 2011.

COLLI JÚNIOR, Olavo. A eficácia normativa dos tratados internacionais de direitos humanos antes e depois da EC 45. Revista on line Pitágoras. 2011, n. 2. Disponível em: <http://www.finan.com.br/revista/artigo/37>. Acesso em: 27 nov. 2011.

CONCEIÇÃO, José Antônio. Conselho de Segurança da ONU e sua imprescindível reforma. Diálogo e Interação. v.2. Disponível em:

$<$ http://www.faccrei.edu.br/gc/anexos/diartigos27.pdf >. Acesso em: 27 nov. 2011.

ESTATUTO DE ROMA DO TRIBUNAL PENAL INTERNACIONAL. Roma, 17 jul. 1998. Disponível em: < http://www.planalto.gov.br/ccivil_03/decreto/2002/D438 8.htm>. Acesso em: 05 jul.2010.

FERRAJOLI, Luigi. A soberania no mundo moderno: nascimento e crise de Estado nacional. $1^{a}$ ed. São Paulo: Martins Fontes, 2002.

GALVÃO, Bruno Haddad. Direitos do homem, direitos humanos e direitos

fundamentais. SOS Concurseiros. 19 jun. 2008. Disponível em

$<$ http://www.sosconcurseiros.com.br/direito-internacional-e-humanos/assuntosquentes/direitos-do-homem-direitos-humanos-e-direitos-fundamentais_33-71_1/>. Acesso em: 26 nov. 2011.

JARDIM, Tarcísio Dal Maso. O Tribunal Penal Internacional e sua Importância para os Direitos Humanos. In: CÂMARA DOS DEPUTADOS. Comissão de Direitos Humanos. O que é o Tribunal Penal Internacional. Poder Legislativo, Brasília, DF, fev. 2000. Disponível em:

http://www.dhnet.org.br/dados/cartilhas/dh/tpi/cartilha_tpi.htm. Acesso em: 28 nov. 2011.

KIRSCH, Philippe; Q.C.; OOSTERVELD, Valerie. A Comissão Preparatória PósConferência de Roma. In: AMBOS, K.; CARVALHO, Salo de.(Org.). O Direito Penal no Estatuto de Roma: Leituras sobre os Fundamentos e a Aplicabilidade do Tribunal Penal Internacional. Rio de Janeiro: Lumen Juris, 2005. p. 49-60. 
KIRSCH, Philippe; Q.C.; ROBINSON, Darryl. A Construção do Acordo na Conferência de Roma. In: AMBOS, K.; CARVALHO, Salo de.(Org.). O Direito Penal no Estatuto de Roma: Leituras sobre os Fundamentos e a Aplicabilidade do Tribunal Penal Internacional. Rio de Janeiro: Lumen Juris, 2005. p. 21-47.

LEWANDOWSKI, Enrique Ricardo. O Tribunal Penal Internacional: de uma cultura de impunidade para uma cultura de responsabilidade. Estudos Avançados. São Paulo, v.16, n. 45, 2002. Disponível em:

$<$ http://www.scielo.br/scielo.php?script=sci_arttext\&pid=S0103-40142002000200012>. Acesso em: 28 nov. 2011.

MAIA NETO. Cândido Furtado. Direito penal internacional e direito internacional penal: Legislação cosmopolita à luz dos Direitos Humanos e a norma constitucional brasileira aplicada. 2008. Disponível em: $<$ http://br.monografias.com/trabalhospdf901/direito-penal-internacional/direito-penal-internacional.pdf $>$. Acesso em: 26 nov. 2006.

MANDUCA, Paulo César. Panorama dos direitos humanos nas relações internacionais. In: XVI Congresso Nacional do CONPEDI. Anais eletrônicos. Belo Horizonte, 2007. Disponível em:

$<$ http://www.conpedi.org.br/manaus/arquivos/anais/bh/paulo_cesar_manduca.pdf $>$. Acesso em: 27 nov. 2011.

MONT'ALVERNE. Tarin Cristino Frota. O futuro do Conselho de Segurança da ONU: ainda é possível reformá-lo? In: XIX Encontro Nacional do CONPEDI. Anais Eletrônicos. Fortaleza, 2010. Disponível em:

$<$ http://www.conpedi.org.br/manaus/arquivos/Anais/Tarin $\% 20$ Cristino $\% 20$ Frota $\% 20 \mathrm{M}$ ontAlverne.pdf $>$. Acesso em: 28 nov. 2011.

OLIVEIRA, Cristiano José Martins de. A criação de um tribunal penal internacional. In: Jus Navigandi. 2010. Disponível em: <http://jus.com.br/revista/texto/14525/acriacao-de-um-tribunal-penal-internacional/1>. Acesso em 28 nov. 2011.

OLIVEIRA, Gabriela Werner. Os aspectos jurídico-políticos da relação entre o Conselho de Segurança da ONU e o Tribunal Penal Internacional. 2010. 73f. Monografia (Graduação em Direito) - Universidade de Passo Fundo. Disponível em: http://repositorio.upf.br/xmlui/bitstream/handle/123456789/95/PF2010GabrielaWerner Oliveira.pdf? sequence $=1$. Acesso em 28 nov. 2011 .

ORGANIZAÇÃO DAS NAÇÕES UNIDAS. Carta das Nações Unidas. 1945. Disponível em: <http://www.un.org/en/documents/charter/chapter7.shtml>. Acesso em: 25 nov. 2011. 
ORGANIZAÇÃO DAS NAÇÕES UNIDAS. Resolução 3314/1974. Assembleia Geral, 1974, anexo I. Disponível em: $<$ http://daccess-ddsny.un.org/doc/RESOLUTION/GEN/NR0/739/16/IMG/NR073916.pdf?OpenElement>. Acesso em: 24 nov. 2011.

SABÓIA. Gilberto Vergne. A criação do Tribunal Penal Internacional. Revista CEJ. Vol. 4, n. 11, mai./ago, 2000. Disponível em:

$<$ http://www.dhnet.org.br/direitos/sip/tpi/tpi_saboia.html>. Acesso em: 28 nov. 2011.

SEITENFUS, Ricardo. Manual das Organizações Internacionais. $4^{\mathrm{a}}$ edição. Porto Alegre: Livraria do Advogado, 2005.

SEITENFUS, Ricardo; VENTURA, Deyse. Direito Internacional Público. $4^{\mathrm{a}}$ ed. Porto Alegre: Livraria do Advogado, 2006.

TRINDADE, Antônio Augusto Cançado. O direito Internacional em um mundo de transformação (Ensaios 1976 - 2001). Rio de Janeiro: Renovar, 2002.

VIOTTI, Aurélio Romanini de Abranches. Ações Humanitárias pelo Conselho de Segurança: entre a Cruz Vermelha e Clausewitz. Brasília: FUNAG, 2004. 